\title{
Face value: Amygdala response reflects the validity of first impressions
}

\author{
Nicholas O. Rule ${ }^{\mathrm{a}, *}$, Joseph M. Moran ${ }^{\mathrm{b}}$, Jonathan B. Freeman ${ }^{\mathrm{c}}$, Susan Whitfield-Gabrieli ${ }^{\mathrm{b}}$, \\ John D.E. Gabrieli ${ }^{\mathrm{b}}$, Nalini Ambady ${ }^{\mathrm{c}}$ \\ ${ }^{\text {a }}$ University of Toronto, Toronto, ON, Canada \\ ${ }^{\mathrm{b}}$ Massachusetts Institute of Technology, Cambridge, MA, USA \\ c Tufts University, Boston, MA, USA
}

\section{A R T I C L E I N F O}

\section{Article history:}

Received 28 December 2009

Revised 15 May 2010

Accepted 7 July 2010

Available online 12 July 2010

\section{Keywords:}

First impressions

Face perception

Nonverbal behavior

Amygdala

Leadership

\begin{abstract}
A B S T R A C T
The human amygdala responds to first impressions of people as judged from their faces, such as normative judgments about the trustworthiness of strangers. It is unknown, however, whether amygdala responses to first impressions can be validated by objective criteria. Here, we examined amygdala responses to faces of Chief Executive Officers (CEOs) where real-world outcomes could be measured objectively by the amounts of profits made by each CEO's company. During fMRI scanning, participants made incidental judgments about the symmetry of each CEO's face. After scanning, participants rated each CEO's face on leadership ability. Parametric analyses showed that greater left amygdala response to the CEOs' faces was associated with higher post-scan ratings of the CEOs' leadership ability. In addition, greater left amygdala response was also associated with greater profits made by the CEOs' companies and this relationship was statistically mediated by external raters' perceptions of arousal. Thus, amygdala response reflected both subjective judgments and objective measures of leadership ability based on first impressions.
\end{abstract}

(c) 2010 Elsevier Inc. All rights reserved.

\section{Introduction}

Individuals form impressions of other people based on mere glimpses of them (Macrae and Bodenhausen, 2000; Zebrowitz, 1997). Moreover, individuals tend to agree in their judgments of others, even when both the judges and the targets vary in race, nationality, and culture, and even when the judgments are based solely on others' facial appearance (Albright et al., 1997; Zebrowitz et al., 1993). Judgments based on first impressions have been found to predict realworld outcomes. For instance, one study found that judgments of instructors' teaching effectiveness from brief, silent video clips significantly correlated with their students' end-of-semester teaching evaluations and their supervisors' ratings of their work (Ambady and Rosenthal, 1993). However, the criterion variable in this case was somewhat subjective because teaching effectiveness is gauged by student ratings that are based upon subjective judgments.

First impressions have also been related to objective, external criteria, which can be used to measure the predictive validity of those impressions. For instance, men's sexual orientations can be judged at levels significantly greater than chance from facial photographs (Rule et al., 2008). Moreover, another study found that impressions of personality traits and leadership ability judged from the faces of Chief Executive Officers (CEOs) were related to the amounts of profits that

\footnotetext{
* Corresponding author.

E-mail address: nicholas.rule@tufts.edu (N.O. Rule).
}

the CEOs' companies earned (Rule and Ambady, 2008, 2009). In this case, subjective impressions of faces corresponded to an objective measure of success. Given that financial measures, such as company profits, are considered to be an excellent measure of a CEO's ability as a leader (Kaiser et al., 2008), the predictive validity offered by subjective judgments of leadership predicting the success of a leader's organization might be considered an indication that these perceptions were accurate (Funder, 1995; Kruglanski 1989).

One brain region believed to play an important role in our first impressions of others is the amygdala (Schiller et al., 2009). Numerous studies have shown that individuals' evaluations of others' social traits based on photos of their faces recruit the amygdala bilaterally (Freeman et al., 2010). For instance, evaluations of a multitude of traits (e.g., leadership ability, trustworthiness, responsibility, intelligence, competence, aggressiveness, attractiveness, and sociability) have been associated with amygdala responses in individuals viewing others' faces while being scanned with functional magnetic resonance imaging (fMRI; Rule et al., 2010; Todorov and Engell, 2008; Winston et al., 2002). Perhaps the most robust evidence for the amygdala's involvement in assessing others' traits comes from brain lesion studies, which have shown that individuals without functioning amygdalae are substantially impaired in their ability to evaluate certain traits of others from their faces, such as approachability and trustworthiness (Adolphs et al., 1998, 2002).

In all of these studies, though, the actual traits of the target people were unknown. Instead, independent raters judged a set of faces and the consensus among the judges' subjective opinions was used as the criterion by which the faces were considered to be, for example, 
trustworthy or untrustworthy. Thus, because all of the above studies used subjective judgments about unfamiliar people based on facial appearance, it is unknown whether these amygdala responses are the manifestation of just perceivers' stereotypes and impressions or if they might also be valid indicators of objective criteria. In the present study we were therefore interested in testing whether the amygdala might respond to aspects of faces that predict objective measures of people.

Various hypotheses have been offered to explain the amygdala response to social traits. Whereas some have suggested that the amygdala response largely encapsulates basic judgments of valence (with greater responses to negative over positive stimuli; e.g., Todorov and Engell, 2008), others have shown evidence that amygdala response scales with the level of arousal that a stimulus evokes (with greater responses to stimuli that are more arousing; e.g., Anderson et al., 2003). Somewhat related to the arousal theory, a number of human and animal studies have suggested that the amygdala serves an important function in evaluating the motivational salience of stimuli (Amaral, 2002; Cunningham et al., 2008; Phelps and LeDoux, 2005; Schiller et al., 2009). Given that previous behavioral and theoretical work has shown leaders to be perceived by others as high in motivational significance (e.g., Bluedorn and Jaussi, 2008; Kaiser et al., 2008; Kaplan et al., 2008), we were curious about the relationship between amygdala response during the perception of leaders' faces and the possible mediating role of arousal. Specifically, we hypothesized that, when perceiving the faces of leaders, the amygdala would respond to actual leadership ability and that these responses would be tied to arousal, predicting both subjective impressions of leadership ability and objective indicators of leadership success.

To test these hypotheses, we examined individuals' brain responses, as measured by fMRI, during the incidental perception of the faces of CEOs of Fortune 1000 companies. Participants judged each face on a non-social, visually related task (judgments of facial symmetry) while being scanned with fMRI. After scanning, participants saw the CEOs' faces again and were asked to make an explicit judgment of how successful each person would be at leading a company. Previous work has shown that individuals' subjective leadership judgments of politicians were reflected in bilateral amygdala response with the faces of those believed to be better leaders eliciting a significantly greater response than the faces of those believed to be worse leaders (Rule et al., 2010). We expected the amygdala to respond to subjective evaluations of the CEOs' leadership ability but were primarily interested in whether the magnitude of amygdala activation to the CEOs' faces might correlate with an objective indicator of their leadership ability: the performance of their organizations as measured by company profits. In both analyses, we focused on the bilateral amygdala as an a priori region of interest (ROI).

\section{Method}

Sixteen healthy, right-handed undergraduates (ages: 18-23, $M=20.06, S D=1.69 ; n=9$ male) participated in exchange for monetary compensation. Headshot photographs of Chief Executive Officers (CEOs) whose companies ranked in the Fortune 1000: 2006 were downloaded from the companies' websites. Targets were taken from the top 25 and bottom 25 ranks of the Fortune 1000: 2006. Of these 50 CEOs, one CEO was female. One male CEO was not included because previous judgments showed him to be a statistical outlier (Rule and Ambady, 2008). In addition to these 49 targets, the 19 remaining female CEOs from the Fortune 1,000: 2006 were added to the stimulus set, drawn from various ranks throughout the Fortune 1,000 (see Rule and Ambady, 2009). Each photo was converted to grayscale and standardized for size, image resolution, and luminosity.

\section{Procedure}

Participants were told that they would be presented with a series of faces and that their task was to indicate via button-press whether each face was approximately symmetrical or asymmetrical. They were informed that they would have only $2 \mathrm{~s}$ to make their judgment (the length of the TR; see fMRI design below), at which point the trial would end. Each face remained on the screen for the entire $2 \mathrm{~s}$, regardless of when the participant made the response (see Fig. 1).

The faces were presented in random order and the order of targets versus null trials of fixation (i.e., the presentation of a fixation cross; range 0-6 TR's, 0-12 s) was pseudo-randomized into 3 orders using the Counter script designed for Matlab, which spaces each condition's trials so as to optimize the efficiency of blood-oxygenation-leveldependent (BOLD) signal estimation (Dale and Buckner, 1997). Participants were presented with equal numbers of faces and fixation. Null (fixation) trials were not modeled so as to serve as a baseline.

After scanning, participants were presented with each of the faces in random order on a laptop computer. Participants were instructed to rate each face as to how successful they believed the person would be at leading a company from "Not at all successful" (1) to "Very Successful" (7) by using the computer's number keys (Cronbach's $\alpha=0.73$ ). Participants were then asked to indicate whether they recognized any of the faces shown in the experiment. One participant reported recognizing one of the targets and was therefore excluded from data analysis. All stimuli were presented using DirectRT software, both for the in-scan and post-scan presentations.

\section{fMRI design}

Data were acquired using a Siemens Magnetom Tim Trio 3-T scanner housed at the Athinoula A. Martinos Imaging Center at the McGovern Institute for Brain Research at MIT. Functional images consisted of 32 ( $5 \mathrm{~mm}$ thick with $1 \mathrm{~mm}$ slice gap) oblique-axial slices, parallel to the AC-PC line and acquired in interleaved order (in-plane resolution: $3.125 \mathrm{~mm}^{2}$ ). Single-shot gradient echo EPI imaging was used with a TR of $2 \mathrm{~s}$, TE of $30 \mathrm{~ms}$, and flip angle of $90^{\circ}$. Data were collected in a single run consisting of 136 volumes.

Functional data were analyzed in an event-related design using SPM2. Data for each participant were realigned to the mean BOLD EPI image, normalized, and smoothed with a Gaussian kernel of $8 \mathrm{~mm}$ FWHM to reduce noise. Regressors for motion correction were generated and outlier time-points were identified using publicly available in-house software (http://web.mit.edu/swg/software.htm).

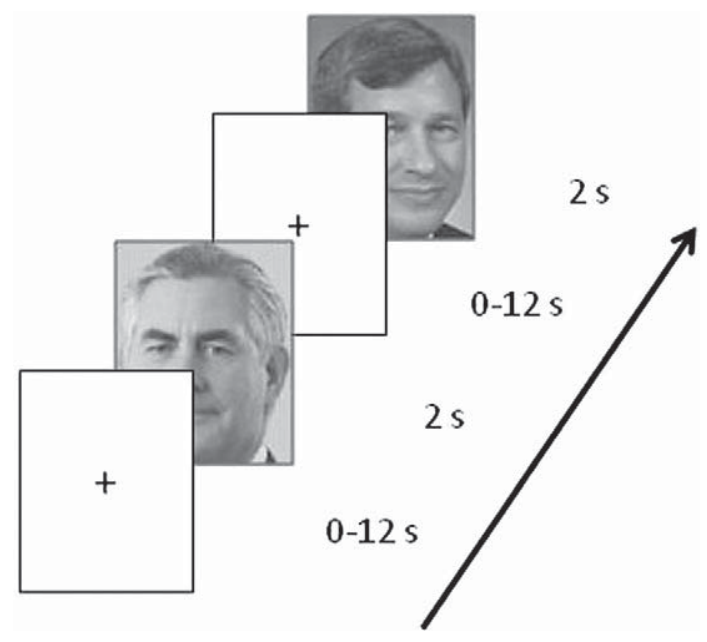

Fig. 1. Examples of stimuli and procedure: participants viewed CEOs' faces in a random order with variable stimulus onset asynchrony jittered between the face presentations, ranging from 0 to $12 \mathrm{~s}$. Each face was presented for a fixed duration of $2 \mathrm{~s}$. 
Parametric predictors for CEOs' revenues and profits were constructed based on company earnings during fiscal year 2005. These values were obtained from the Fortune 1000 listing, available from the Fortune website (http://money.cnn.com/magazines/fortune/fortune500) and transformed using the natural logarithm to achieve normality. Parametric predictors were also constructed for participants' mean post-scan leadership ratings.

\section{fMRI analysis}

Given our a priori hypothesis of amygdala involvement, we examined BOLD responses in anatomically-defined ROIs, the right and left amygdalae defined by the AAL atlas (total volume $=3744 \mathrm{~mm}^{3}$; Tzourio-Mazoyer et al., 2002), and applied a small-volume correction for multiple comparisons in the region of interest. We conducted second-level random-effects general linear model (GLM) analyses to interrogate our ROIs. These GLMs modeled face presentation and, critically, parametric predictors of both subjective/consensus-based and objective/accurate measures of CEO success corresponding to the faces trial-by-trial.

As no previous study has examined neural correlates of the accurate judgment of others, we also conducted an additional exploratory whole-brain analysis at a liberal threshold (voxel-wise $p$-uncorrected $=0.005$, extent-threshold $=5$ voxels) to investigate what other regions may subserve accuracy in first impressions.

In addition, to ensure that the effects could not be accounted for by facial attractiveness or affect, separate groups of independent raters coded each face for attractiveness $(n=7$; Cronbach's $\alpha=0.72)$ and affective expression ( $n=2$; Cronbach's $\alpha=0.87$ ). Participants viewed each face presented on a computer screen in a random order and provided a rating from 1 ("Not at all attractive" or "Neutral", respectively) to 7 ("Very attractive" or "Very happy", respectively). Ratings for each face were averaged across participants and the mean ratings were used as covariates in the analyses. No participant reported familiarity with any of the faces.

Finally, we were interested in exploring the basis for the amygdala response to the CEOs' faces as it relates to company profits. Previous research has reported valence and arousal to be basic critical dimensions underlying amygdala responses to various social and non-social stimuli (e.g., Anderson et al., 2003; Todorov and Engell, 2008). We therefore believed that they may serve as potential mediators of the relationship observed between company profits and amygdala response. To test this, we asked external raters $(n=12)$ to judge the valence (Cronbach's $\alpha=0.76$ ) and arousal (Cronbach's $\alpha=0.83$ ) of the CEOs' faces according to how positive/negative they found each face [anchored at "Extremely negative" (1), "Neither negative nor positive" (4), and "Extremely positive" (7)], immediately followed by a rating of the intensity of that feeling [anchored at "Weakest intensity" (1), "Moderate intensity" (4), and "Greatest intensity" (7)] with the explanation that positive (e.g., a puppy) and negative (e.g., a bomb) stimuli, while opposite in valence, can be equally intense. The mean judgments for each face were then used to construct separate GLMs for each participant in which each CEO's face was modeled with a separate regressor that contrasted the presentation of each CEO's face against baseline (fixation). Contrast values ( $B$ coefficients) were then extracted using Marsbar (Brett et al., 2002), aggregated across participants into a single vector, and entered as predictor variables into statistical mediation models (see Baron and Kenny, 1986) in SPSS.

\section{Results}

The magnitude of participants' left amygdala responses correlated positively with company profits such that they responded more when viewing the faces of CEOs whose companies earned more profit and less when viewing the faces of CEOs whose companies earned less profit (cluster-wise $p$-corrected $=0.031, k=7$, maximum $Z=3.27$; MNI: $-27,-6,-15$; Fig. 2). No such relation was observed in the right amygdala. Thus, there was a significant relation between left amygdala activation and an objective measure of performance: the profits of companies led by the CEOs whose faces were viewed during scanning.

For exploratory purposes, we conducted an additional whole-brain analysis at a more liberal threshold (voxel-wise $p$-uncorrected $=0.005$; extent-threshold $=5$ voxels) to investigate the regions outside of the a priori hypothesized amygdala that may be positively correlated with the company profits associated with the faces of the CEOs. The most significant positive correlation between activation magnitude and profits across the entire brain was in the left amygdala (MNI: $-27,-6,-15 ; k=12$; maximum $Z=3.27$; voxel-wise $p$ uncorrected $=0.001$; Fig. 3, panel A). Only two other regions showed a relation with CEOs' company profits: one in the right temporoparietal junction (TPJ; MNI: $54,-36,21 ; k=7$; maximum $Z=2.83$; voxel-wise $p$-uncorrected $=0.002$; see Fig. 3 , panel B) and another in the left superior temporal sulcus (STS; MNI: $-57,-6,3 ; k=12$; maximum $Z=2.95$; voxel-wise $p$-uncorrected $=0.002$; Fig. 3, panel A). Noting the relevance of targets' gender to the perception of leaders (e.g., Eagly and Karau 2002; Rule and Ambady, 2009) we also conducted a 2 (participant gender) $\times 2$ (target gender) $\times 3$ (ROI) ANOVA with repeated measures on the last two factors based on contrast values for each participant's response to the male and female CEOs' faces extracted from the left amygdala, left STS, and right TPJ clusters that were active in the above analysis (i.e., masks were created to include all functional voxels). This analysis showed no significant main effects or interactions (all $F \mathbf{s}<2.12$, all $p^{\prime} \mathrm{s}>0.17$ ).

We then conducted further a priori amygdala and exploratory whole-brain analyses to examine the relation between activation magnitudes and another measure of corporate performance that is a less valid index of companies' success: company revenues. As expected, no significant correlations were observed. This suggests that the correlations observed above were related to company success rather than to company size, which has a strong influence on company revenues (i.e., does not account for operation costs and losses). Similarly, participants' ratings of facial symmetry during the scan were also unrelated to amygdala response.

Similar analyses were performed to examine the relation between the magnitudes of amygdala activations and participants' post-scan subjective judgments of leadership. There was a significant positive correlation between left amygdala activation and perceived leadership ability (cluster-wise $p$-corrected $=0.021, k=10$, maximum $Z=3.65$; MNI: $-21,-3,-24$; Fig. 4). Thus, the better a leader a CEO was perceived to be, the more participants' left amygdalae had

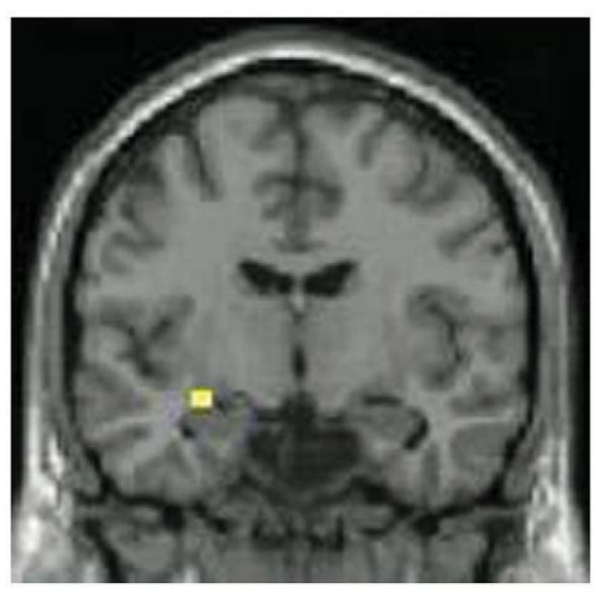

Fig. 2. Left amygdala region where activation to faces of CEOs increased significantly in relation to an objective real-world index: profits from the companies led by those CEOs. 
A

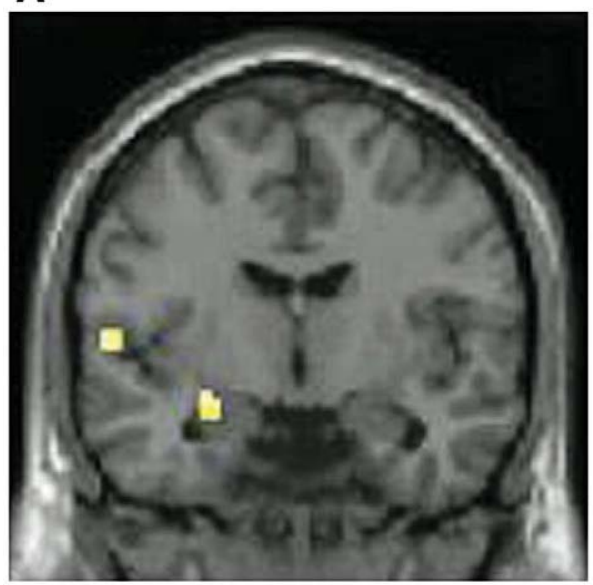

B

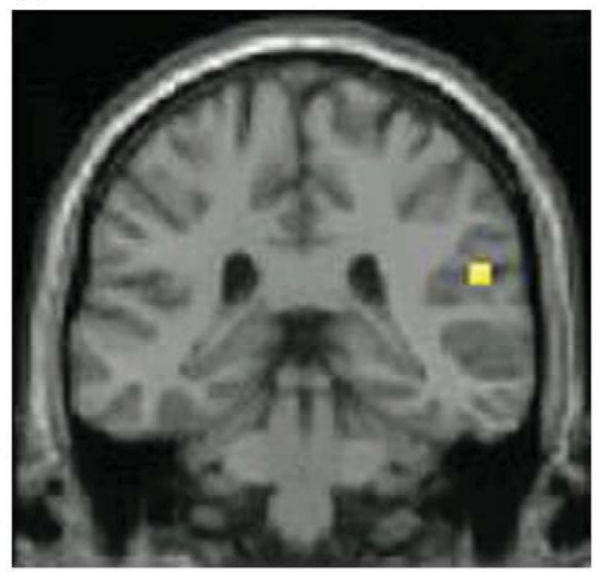

Fig. 3. Regions from a whole-brain analysis where activation increased significantly in relation to an objective criterion (company profits) when perceiving CEOs' faces: (A) left amygdala and left superior temporal sulcus, (B) right temporo-parietal junction.

responded when perceiving that CEO's face during the scan. As above, neither perceivers' nor targets' gender modulated this effect (all $F s<0.65$, all $p$ 's $>0.44$ ) or the participants' behavioral ratings of leadership ability (all $F s<2.51$, all $p$ 's $>0.14$ ).

External raters' judgments of the affect and attractiveness of the faces were not related to any response in either the left or right

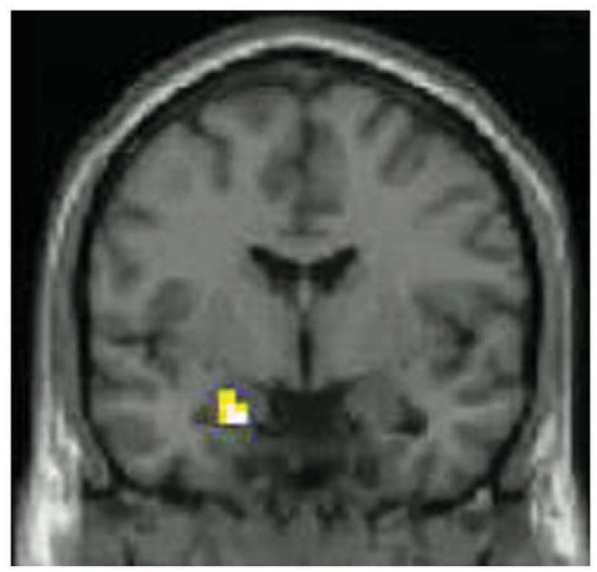

Fig. 4. Left amygdala region where activation to CEOs' faces increased significantly in relation to participants' consensual, subjective impressions of perceived leadership success. amygdala. Because attractiveness judgments were correlated with participants' post-scan leadership ratings $(r=0.41, p<0.001)$, however, we repeated the above analyses for company profits and leadership success with attractiveness scores entered into the regression simultaneously as a covariate. The relations between left amygdala response and both profits and perceived leadership ability remained significant after controlling for attractiveness; cluster-wise $p$ 's-corrected $<0.035$.

Finally, we investigated the extent to which separate perceivers' impressions of valence and arousal from the CEOs' faces might mediate the relationship between the responses observed in the left amygdala and the objective criterion for the CEOs' success: company profits. We conducted an items-based analysis in which we obtained every participant's neural response to each CEO's face as compared to baseline (i.e., wherein the face was the unit of analysis). We then extracted the contrast values for each CEO's face from a functional ROI representing the cluster of activation in the left amygdala that was responsive to company profits. The mean signal in this ROI for each face was then used as the predictor variable in mediation models in which company profits served as the outcome variable and valence and arousal, respectively, as mediators.

Due to the relatively small sample sizes in the current study, we estimated the mediation models using bootstrapping at 1,000 iterations per model. Results of the models showed that arousal significantly mediated the relationship between left amygdala response and company profits: $95 \% \mathrm{CI}=0.03-0.43$; see Fig. 5, panel A. Ratings of valence, however, did not mediate the relationship: $95 \%$ $\mathrm{CI}=-0.01$ to 0.20 . Given that arousal significantly mediated the relationship between amygdala response and company profits, and because perceptions of arousal are theoretically less complex than assessments of leadership, we were curious as to whether arousal might also account for the relationship between perceptions of leadership ability and company profits observed in previous studies (Rule and Ambady, 2008, 2009). The results of these models showed that arousal significantly, but only partially, mediated the relationship between leadership and company profits $(95 \% \mathrm{CI}=0.06-0.93$; see Fig. 5, panel B), whereas valence again did not mediate the relationship ( $95 \% \mathrm{CI}=-0.32$ to 0.61 ).

As arousal only partially mediated the relationship between perceptions of leadership and company profits, it seems that perceptions of leadership may carry some unique variance apart from arousal in predicting company profits. We therefore hypothesized that a model accounting for both arousal and perceived leadership as mediators of the relationship between amygdala response and company profits would provide a stronger account of the predictive relationships observed in the data. Specifically, we fit a modified path model using regression analyses that sequentially modeled arousal as a partial mediator of the relationship between amygdala response and perceived leadership (95\% $\mathrm{CI}=0.00-0.05$; Fig. 6, panel A), and perceived leadership as a partial mediator of the relationship between arousal and company profits $(95 \% \mathrm{CI}=0.07-$ 4.21; Fig. 6, panel B). As expected, a regression equation in which amygdala response, arousal, and perceived leadership simultaneously predicted company profits was a significantly stronger predictive model than that in which leadership $\left[\Delta R^{2}=0.05, F(1,64)=3.91\right.$, $p=0.05$; $95 \%$ CI for single-mediator model $=0.00-0.60$, see Fig. 6 , panel C] or arousal $\left[\Delta R^{2}=0.09, F(1,64)=7.30, p=0.009\right]$ served as solitary predictors (Fig. 5, panel C); despite being significantly correlated $[r(66)=0.27, p=0.026]$, leadership and arousal were not collinear: tolerances $>0.87$. Last, we fit two regression models that included facial attractiveness and ratings of valence as additional predictors of company profits. Neither the model including attractiveness $\left[\Delta R^{2}=0.01, F(1,63)=0.99, p=0.32\right]$ nor the model including both attractiveness and valence $\left[\Delta R^{2}<0.01, F(1,62)=\right.$ $0.01, p=0.94$ ] produced significantly better predictions of company profits than did the simultaneous model, suggesting that arousal and 

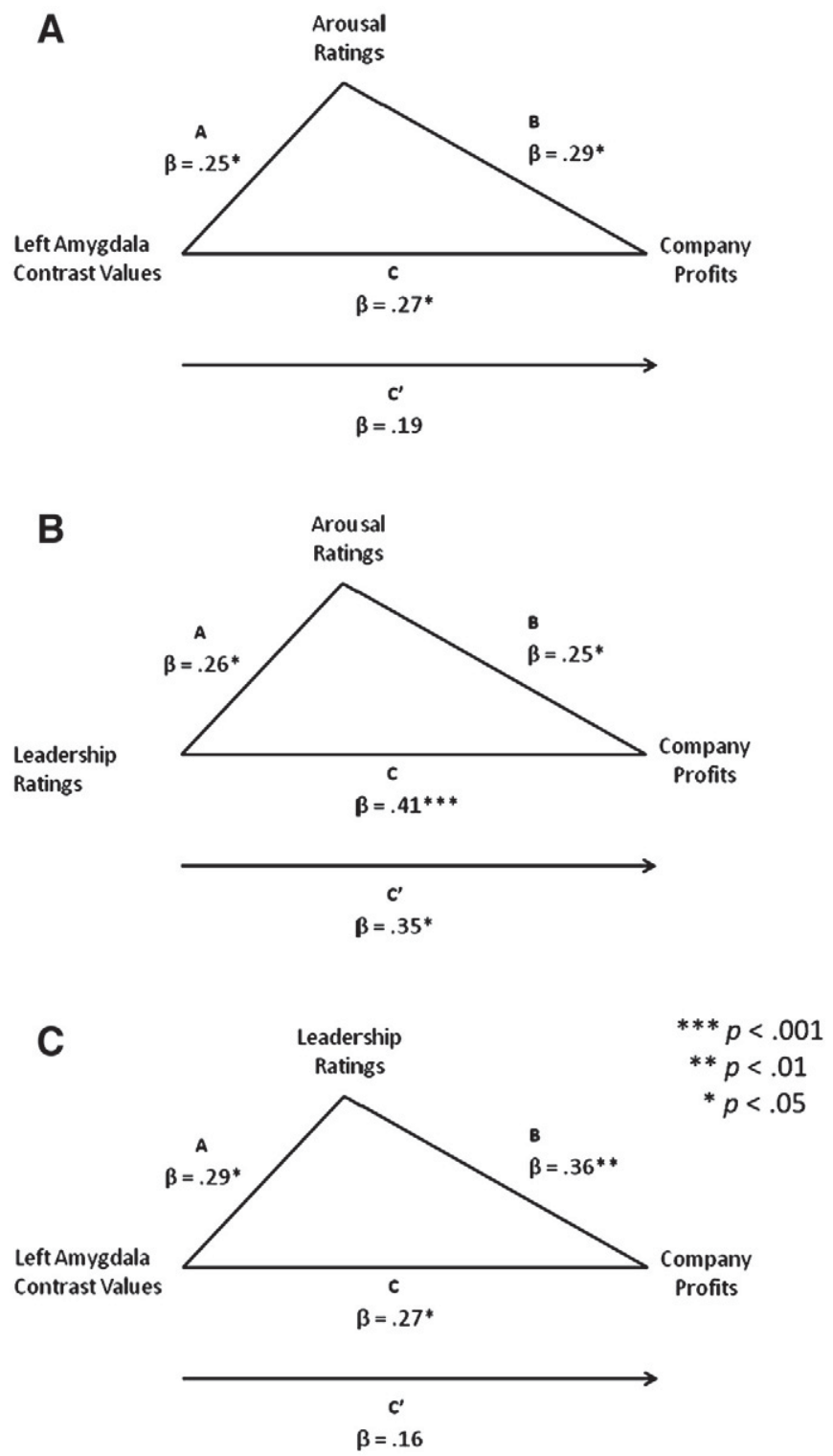

Fig. 5. Standardized regression coefficients and levels of significance for the mediation model in which (A) participants' mean response in the left amygdala to the faces of each CEO significantly predicted the CEOs' company profits (path $\mathrm{C}$ ) but was mediated by the inclusion of external raters' arousal ratings, rendering the relationship between amygdala response and company profits non-significant when arousal ratings were included in the model (path $\mathrm{C}^{\prime}$ ); response to company profits in the left amygdala was significantly related to the arousal ratings (path A) and arousal ratings were significantly related to company profits when controlling for amygdala response (path B), (B) perceptions of leadership ability from the CEOs' faces significantly predicted their companies' profits (path $C$ ) but were mediated by the inclusion of external raters' arousal ratings, reducing the significance of the relationship between leadership and company profits when arousal ratings were included in the model (path $C^{\prime}$ ) in evidence of partial mediation; perceptions of leadership were significantly related to the arousal ratings (path A) and arousal ratings were significantly related to company profits when controlling for perceptions of leadership (path B), and (C) participants' mean response in the left amygdala to the faces of each CEO significantly predicted the CEOs' company profits (path C) but was mediated by the inclusion of perceptions of leadership ability, rendering the relationship between amygdala response and company profits non-significant when leadership ratings were included in the model (path $\mathrm{C}^{\prime}$ ); response to company profits in the left amygdala was significantly related to the leadership ratings (path A) and leadership ratings were significantly related to company profits when controlling for amygdala response (path B).

leadership are uniquely relevant to predicting company profitsrather than the increase in prediction simply being due to the inclusion of additional factors (see Table 1 ).
To verify the inferred causal model by which left amygdala response predicts company profits via arousal and leadership ratings, we tested the model using AMOS structural equation modeling software (see Fig. 7). Specifically, we modeled the causal path that amygdala responses should predict arousal, which should predict perceived leadership, which should predict company profits, with the inclusion of indirect predictive paths between amygdala response and company profits via both arousal and perceived leadership. The relationships between the estimates predicted by the model and the observed estimates measured by the data showed a non-significant difference $\left[\chi^{2}(1, N=68)=1.06, p=0.30\right]$, indicating a close fit. Moreover, both the comparative fit index (CFI $>0.99)$ and normed fit index ( $\mathrm{NFI}=0.97$ ) exceeded the 0.95 criterion to support the model's goodness of fit, and the root mean square error of approximation (RMSEA $<0.03$ ) was well below the 0.08 threshold, indicating a very good fit of the model as well. Thus, the hypothesized path model was deemed an acceptable explanation of the data and accounted for a greater percentage of explained variance in company profits $\left(R^{2}=0.23\right)$ than either the direct path from left amygdala response or from the modeling of the solitary indirect predictors, arousal and perceived leadership.

\section{Discussion}

We found evidence that the human amygdala responds to first impressions of faces of unknown CEOs in a way that relates both to an objective measure of effective leadership, the profits earned by the companies led by those CEOs, and to a subjective judgment about the leadership ability of those CEOs. The magnitudes of left amygdala responses to CEOs' faces increased as a consequence of the size of profits earned by the companies led by the CEOs and also as a consequence of how participants rated their apparent leadership ability. The relationship between amygdala response and company profits was mediated by external raters' perceptions of arousal from the faces, which also had direct effects upon perceivers' subjective impressions of leadership ability. This suggests that the CEOs of more successful companies may elicit a greater response in the left amygdala and may be judged to be better leaders because their faces are more arousing. Thus, the left amygdala responded to CEOs' faces according to their success, as measured by both objective and subjective criteria.

We controlled for several factors that have been thought to play a role in amygdala activation. Facial attractiveness rated by a different set of judges, which is known to bear an important influence on social judgments (e.g., Zebrowitz, 1997) and has been previously found to elicit an amygdala response (Aharon et al., 2001; Winston et al., 2007) showed no relation with amygdala activation during perceptions of the CEOs' faces. In addition, when facial attractiveness scores for each CEO were entered into the analyses as a covariate, responses in the left amygdala in relation to both company profits and ratings of leadership success remained significant. Similarly, neither ratings of emotional expression by a different set of judges nor the participants' judgments of the CEOs' facial symmetry, made while perceiving the faces in the fMRI scanner, were related to amygdala activation.

The specific relation between left amygdala activation and leadership success was further supported by the absence of a correlation between amygdala response and company revenues. Company revenues (or gross profits) are highly influenced by company size whereas company profits (or net profits) account for operating costs and overall losses. For example, automobile manufacturers possess some of the highest annual revenues but also some of the highest reported losses, typically leaving them with a relatively small profit margin. Thus, company revenues are not an effective index of success and, as we have shown here, were unrelated to any neural response across the entire brain. The present imaging findings are consistent with behavioral studies showing no relation between 
A

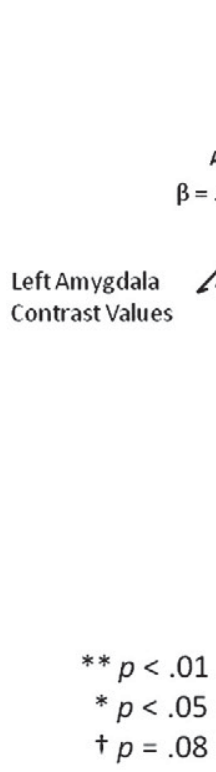

B

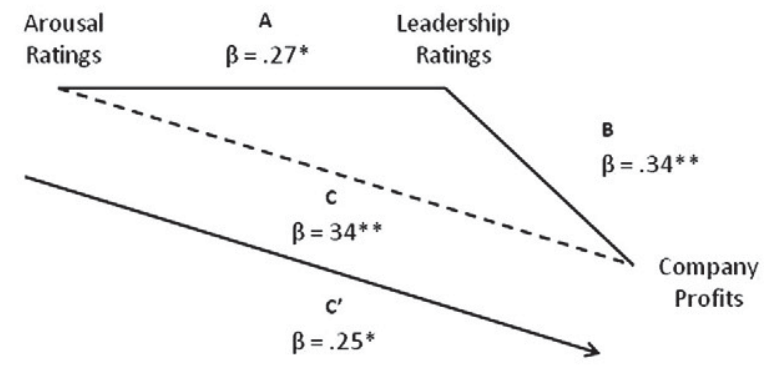

Arousal Leadership

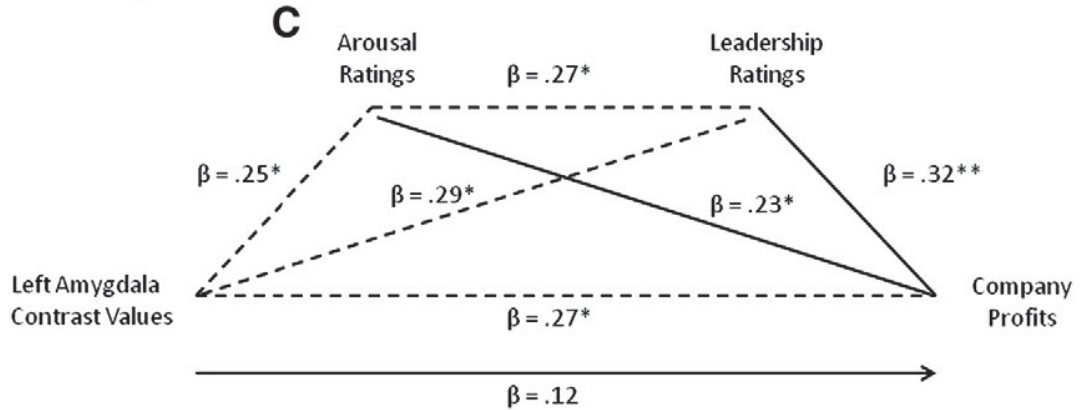

Fig. 6. Sequential-regression modified path analysis consisting of (A) a mediation model in which the significant relationship between participants' left amygdala response and perceptions of leadership (path C) significantly decreased in significance when external raters' arousal ratings were included in the model (path $C^{\prime}$ ); the relationship between amygdala response and arousal is significant (path A) and the relationship between arousal and leadership was marginally significant when controlling for the variance in perceivers' amygdala responses (path B); (B) a mediation model in which the significant relationship between external raters' arousal ratings and CEOs' company profits (path C) significantly decreased in significance when perceptions of leadership ability were included in the model (path $\mathrm{C}^{\prime}$ ); the relationship between arousal and leadership was significant (path A) and the relationship between leadership and company profits was significant when controlling for the variance in ratings of arousal from the CEOs' faces (path B); and (C) the compound model in which mediation of the significant relationship between perceivers' amygdala responses and CEOs' company profits was achieved when arousal and leadership were included as simultaneous predictors of company profits; the solid lines show the effects of the predictor variables (left amygdala response, ratings of arousal, and perceived leadership ability) on the outcome variable (company profits), whereas the dashed lines show the intercorrelations between the predictor variables. The dashed line between left amygdala response and company profits within the trapezoid indicates the direct effect and the detached arrow just below the trapezoid indicates the same path when arousal and leadership are included in the model.

company revenues and perceptions of leadership success (Rule and Ambady, 2008, 2009).

Perceivers' left amygdala response to the CEOs' faces also appears to have occurred automatically upon perceiving the faces. None of the perceivers was aware that they were viewing faces of CEOs and their task while viewing the faces was non-social and unrelated to evaluations of success or leadership. Hence, mere perception of CEOs' faces seemed to elicit a response in the amygdala that

Table 1

Standardized parameter estimates and goodness of fit tests for a nested taxonomy of regression models predicting CEOs' company profits based on perceivers' left amygdala responses and behavioral ratings of the CEOs' faces.

\begin{tabular}{|c|c|c|c|c|c|c|}
\hline & Model 1 & Model $2^{a}$ & Model $3^{a}$ & Model $4^{\mathrm{a}}$ & Model $5^{\mathrm{b}}$ & Model $6^{\mathrm{b}}$ \\
\hline & $\begin{array}{l}\text { Direct } \\
\text { effect }\end{array}$ & $\begin{array}{l}\text { Arousal } \\
\text { mediator }\end{array}$ & $\begin{array}{l}\text { Leadership } \\
\text { mediator }\end{array}$ & $\begin{array}{l}\text { Path } \\
\text { model }\end{array}$ & $\begin{array}{l}\text { Extended } \\
\text { model I }\end{array}$ & $\begin{array}{l}\text { Extended } \\
\text { model II }\end{array}$ \\
\hline $\begin{array}{l}\text { Amygdala } \\
\text { response }\end{array}$ & $0.27^{*}$ & 0.19 & 0.16 & 0.12 & 0.11 & 0.11 \\
\hline $\begin{array}{l}\text { Arousal } \\
\text { ratings }\end{array}$ & & $0.29^{*}$ & & $0.23^{*}$ & $0.23^{*}$ & $0.23 \dagger$ \\
\hline $\begin{array}{l}\text { Leadership } \\
\text { ratings }\end{array}$ & & & $0.36^{* *}$ & $0.32^{* *}$ & $0.36^{* *}$ & $0.37^{* *}$ \\
\hline $\begin{array}{l}\text { Attractiveness } \\
\text { ratings }\end{array}$ & & & & & -0.12 & -0.11 \\
\hline $\begin{array}{l}\text { Valence } \\
\text { ratings }\end{array}$ & & & & & & -0.01 \\
\hline$R^{2}$ & 0.07 & 0.15 & 0.19 & 0.24 & 0.25 & 0.25 \\
\hline$\Delta R^{2}$ & & $0.08^{*}$ & $0.12^{* *}$ & $0.17^{* *}$ & 0.01 & 0.00 \\
\hline
\end{tabular}

${ }^{* *} p<0.01$.

${ }^{*} p<0.05$.

$\dagger p<0.07$

a Compared to Model 1.

b Compared to Model 4. parametrically scaled with both objective and subjective indicators of each CEO's success. This conclusion is consistent with previous studies that have implicated the amygdala in the automatic processing of other social traits (e.g., Winston et al., 2002).

It is not surprising that the amygdala was more responsive to the faces of more successful CEOs. Both lesion studies and neuroimaging work have indicated that the amygdala is centrally involved in the evaluation of socially and emotionally significant stimuli (Adolphs et al., 2002; Cunningham et al., 2008; Phelps, 2006; Schiller et al., 2009; Van Bavel et al., 2008) and there exists evidence that the amygdala response is greater for stimuli that are more arousing (Anderson et al., 2003; Kensinger and Schacter, 2006). Research in leadership and management has suggested that successful CEOs may be those who "stand out" more (Kaiser et al., 2008) by expressing greater dominance or power (Kaplan et al., 2008; Rule and Ambady, 2008, 2009) and may therefore hold greater motivational significance (Bluedorn and Jaussi, 2008). The present finding, that the relationships between company profits and both perceptions of leadership and left amygdala response were mediated by the level of arousal perceived from the CEOs' faces, bridges these two bodies of work and provides insights to how perceivers respond to leaders and form these predictive relationships. Based on our statistical modeling, it appears that arousal links amygdala response to both subjective and objective indices of leadership success, with the former, in turn, predicting the latter. It is therefore reasonable to speculate that the amygdala's sensitivity to perceptions of arousal supports or influences more complex social judgments, such as evaluations of leadership from faces. Thus, whereas earlier work has shown that the amygdala responds to levels of arousal among pictures, words, and smells (e.g., Anderson et al., 2003; Kensinger and Schacter, 2006), the present data suggest that this may extend to faces, as well. 


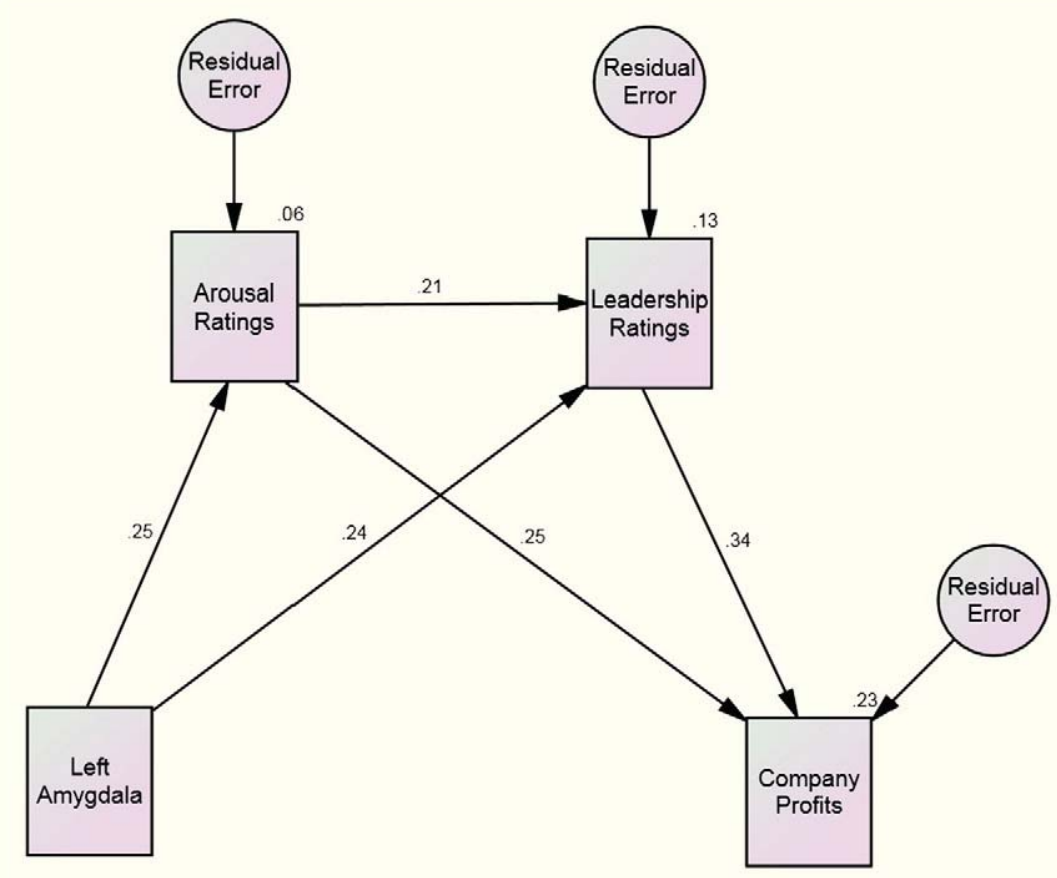

Fig. 7. Conventional path analysis constructed in AMOS demonstrating the indirect effect of perceivers' left amygdala responses upon company profits via ratings of arousal and perceived leadership ability. Path coefficients are standardized ( $\beta$ 's), error variances for the endogenous variables are indicated in ovals, and variances explained (multiple $R^{2}$ values) are adjacent to the endogenous variables.

Additional support can be found in the whole-brain analysis. Although detected at a lower threshold, participants showed a greater response to the faces of more successful CEOs not only in the left amygdala but also in the superior temporal sulcus and temporoparietal junction, all of which are regions implicated in inferring the mental states of others, often referred to as "theory of mind" (Gallagher and Frith, 2003). These data suggest that perceivers may either be engaged in more speculation about the faces of CEOs who are more successful or may be allocating greater attention to more successful CEOs (Mitchell, 2008; Saxe et al., 2006). Both interpretations fit with the notion that more successful CEOs are perceived as more salient or "stand out" more.

Many questions still remain about how and why CEOs' facial appearances vary according to their level of success. In this study, the faces of the CEOs were obtained from their respective companies' internet websites and it is unknown when the photographs were taken relative to the performance of the company. For instance, could it be that companies hire CEOs with the greatest apparent leadership, that executives with a strong sense of leadership choose to work at companies that have the best chance of accruing profits, or even that making a lot of profits makes a CEO feel and look successful? Although we cannot answer these questions in the present work, previous research supports several possibilities. Specifically, some work suggests that innate differences in appearance may advantage particular individuals toward success ("your face is your fate"; Collins and Zebrowitz, 1995). Yet there is also work suggesting that facial appearance is malleable and influenced by life experience (the "Dorian Gray effect"; Zebrowitz et al., 1998). The former hypothesis would suggest that individuals with a particular appearance are advantaged in life. Their appearance might therefore confer upon them the attribution of leadership ability and/or provide them with the opportunities that allow them to become better leaders (Zebrowitz, 1997). That is, being endowed with the look of success may lead one to become successful. The latter hypothesis would suggest that individuals who are successful in navigating the challenges of corporate leadership learn to carry themselves in a certain way (Zajonc et al., 1987). According to the first hypothesis, successful looking individuals might be hired by more successful companies, whereas according to the second hypothesis individuals who lead companies to success may come to reflect this achievement in their appearance. Although there is evidence to support both of these possibilities, other explanations may exist, as well. Thus, further research is needed to disentangle and explore the potential antecedents of these effects.

Future work may also seek to address how these effects might generalize to other populations. That is, are the findings that we observed here exclusive to CEOs, or might they apply to other types of leaders? One previous study asked participants to indicate their preference among pairs of US political candidates and found that, when averaging across the responses of all the participants in the sample, those candidates who were preferred elicited no distinct neural responses but that candidates who were not chosen elicited a response in the anterior cingulate and insula (Spezio et al. 2008). But another study examined the neural activation of American and Japanese participants asked to indicate whether they would vote for individual candidates from two US and Japanese elections. When considering the participants' individual choices about for whom they would vote, both the American and Japanese participants showed significantly greater activation in the bilateral amygdala in response to the faces of the leaders for whom they indicated they would vote, as compared to the leaders for whom they indicated they would not vote. This pattern was found for candidates from both cultures (Rule et al., 2010). Moreover, future work should consider how variables such as group membership might play into these effects. Recent work considering the effects of intergroup differences on the perceptions of leaders has shown that perceivers evaluated Black male CEOs more positively if their faces expressed warmth, rather than power, as it made them seem incongruous with, and thereby disarming of, the stereotype of Black men as aggressive (Livingston and Pearce, 2009). As the present targets were all ostensibly Caucasian, it would be interesting to see whether the current effects replicate for CEOs belonging to racial minority groups. 
The present work raises other questions of interest, as well. For instance, here we observed activation in only the left amygdala but not the right amygdala. Although this left-amygdala specificity is seen in other studies of impression formation (e.g., Schiller et al., 2009), previous work on subjective impressions of leadership has shown bilateral amygdala activation (Rule et al., 2010). This distinction is worthy of further exploration and one key difference that may be relevant is that the current study showed that amygdala response corresponds to assessments of leadership using a continuous measure of relative differences between leaders' faces, whereas the one previous study showing that the amygdala is involved in subjective assessments of leadership modeled the data using a single subtraction based on a dichotomous choice (Rule et al., 2010). Thus, the graded nature of the current data, while perhaps providing a more meaningful effect, may have lacked the same level of statistical power that was observed in the previous work. Similarly, it is interesting that we did not find amygdala activation in response to variation in facial attractiveness or emotional expression, as previous studies have observed (e.g., Aharon et al., 2001; Winston et al., 2007). One explanation for this difference may be that the range of attractiveness and affect among the current faces was much narrower than in the previous studies. This is reasonable, as the previous studies focused on analyses of attractiveness or emotion, whereas those traits were only incidentally considered as covariates in the current work. Nevertheless, additional investigation may be warranted.

Despite these limitations, the current work provides a first look into the brain basis for accuracy in perceiving others. Although there is a sizable literature on the behavioral and neural correspondents to subjective and consensual judgments, there is still a relative dearth of information about social judgments related to objective outcomes (Ambady et al., 2000). The finding that the left amygdala responds both to subjective perceptions and objective indices of others' success suggests a neural mechanism for consensus and accuracy in our first impressions of others.

\section{Acknowledgments}

This work was supported by a National Science Foundation grant (BCS-0435547) to NA and a National Science Foundation Graduate Research Fellowship to NOR. Correspondence concerning this article should be addressed to Nicholas O. Rule, University of Toronto Psychology Department, 100 St. George Street, Toronto, ON M5S 3G3, rule@psych.utoronto.ca.

\section{References}

Adolphs, R., Tranel, D., Damasio, A.R., 1998. The human amygdala in social judgment. Nature 393, 470-474

Adolphs, R., Baron-Cohen, S., Tranel, D., 2002. Impaired recognition of social emotions following amygdala damage. J. Cogn. Neurosci. 14, 1264-1274.

Aharon, I., Etcoff, N., Ariely, D., Chabris, C.F., O'Connor, E., Breiter, H.C., 2001. Beautiful faces have variable reward value: fMRI and behavioral evidence. Neuron 32, 537-551.

Albright, L., Malloy, T.E., Dong, Q., Kenny, D.A., Fang, X., Winquist, L., Yu, D., 1997. Crosscultural consensus in personality judgments. J. Pers. Soc. Psychol. 72, 558-569.

Amaral, D.G., 2002. The primate amygdala and the neurobiology of social behavior: implications for understanding social anxiety. Bio. Psych. 51, 11-17.

Ambady, N., Rosenthal, R., 1993. Half a minute: predicting teacher effectiveness from thin slices of nonverbal behavior and facial attractiveness. J. Pers. Soc. Psychol. 64, 431-441.

Ambady, N., Bernieri, F.J., Richeson, J.A., 2000. Toward a histology of social behavior: Judgmental accuracy from thin slices of the behavioral stream. Adv. Exp. Soc. Psychol. 32, 201-271.

Anderson, A.K., Christoff, K., Stapin, I., Panitz, D., Ghahremani, D.G., Glover, G., Gabrieli, J. D.E., Sobel, N., 2003. Dissociated neural representations of intensity and valence in human olfaction. Nat. Neurosci. 6, 196-202.
Baron, R.M., Kenny, D.A., 1986. The moderator-mediator variable distinction in social psychological research: conceptual, strategic, and statistical considerations. J. Pers. Soc. Psychol. 51, 1173-1182.

Bluedorn, A.C., Jaussi, K.S., 2008. Leaders, followers, and time. Leadersh. Q. 19, 654-668.

Brett, M., Anton, J.L., Valabregue, R., Poline, J.B., 2002. Region of interest analysis using an SPM toolbox. Neuroimage 16 ABS-497.

Collins, M.A., Zebrowitz, L.A., 1995. The contributions of appearance to occupational outcomes in civilian and military settings. J. App. Soc. Psychol. 25, 129-163.

Cunningham, W.A., Van Bavel, J.J., Johnsen, I.R., 2008. Affective flexibility: evaluative processing goals shape amygdala activity. Psychol. Sci. 19, 152-160.

Dale, A.M., Buckner, R.L., 1997. Selective averaging of rapidly presented individual trials using fMRI. Hum. Brn. Mapp. 5, 329-340.

Eagly, A.H., Karau, S.J., 2002. Role congruity theory of prejudice toward female leaders. Psychol. Rev. 109, 573-598.

Freeman, J.B., Schiller, D., Rule, N.O., Ambady, N., 2010. The neural origins of superficial and individuated judgments about ingroup and outgroup members. Hum. Brain Mapp 31, 150-159.

Funder, D.C., 1995. On the accuracy of personality judgment: a realistic approach. Psychol. Rev. 102, 652-670.

Gallagher, H.L., Frith, C.D., 2003. Functional imaging of 'theory of mind'. Trends Cogn. Sci. 7, 77-83.

Kaiser, R.B., Hogan, R., Craig, S.B., 2008. Leadership and the fate of organizations. Amer. Psychol. 63, 96-110.

Kaplan, S.N., Klebanov, M.M., Sorensen, M., 2008. Which CEO characteristics and abilities matter? Paper presented at the annual meeting of the American Financial Association. New Orleans, LA.

Kensinger, E.A., Schacter, D.L., 2006. Processing emotional pictures and words: effects of valence and arousal. Cogn. Aff. Behav. Neurosci. 6, 110-126.

Kruglanski, A.W., 1989. The Psychology of being "right": On the problem of accuracy in social perception and cognition. Psychol. Bull. 106, 395-409.

Livingston, R.W., Pearce, N.A., 2009. The teddy-bear effect: does having a baby face benefit black chief executive officers? Psychol. Sci. 20, 1229-1236.

Macrae, C.N., Bodenhausen, G.V., 2000. Social cognition: thinking categorically about others. Ann. Rev. Psychol. 51, 93-120.

Mitchell, J.P., 2008. Activity in right temporo-parietal junction is not selective for theory of mind. Cereb. Cortex 18, 262-271.

Phelps, E.A., 2006. Emotion and cognition: insights from studies of the human amygdala. Ann. Rev. Psychol. 57, 27-53.

Phelps, E.A., LeDoux, J.E., 2005. Contributions of the amygdala to emotion processing: from animal models to human behavior. Neuron 48, 175-187.

Rule, N.O., Ambady, N., 2008. The face of success: inferences of personality from Chief Executive Officers' appearance predict company profits. Psychol. Sci. 19, 109-111.

Rule, N.O., Ambady, N., 2009. She's got the look: Inferences from female chief executive officers' faces predict their success. Sex. Roles. 61, 644-652.

Rule, N.O., Ambady, N., Adams Jr, R.B., Macrae, C.N., 2008. Accuracy and awareness in the perception and categorization of male sexual orientation. J. Pers. Soc. Psychol. 95, 1019-1028.

Rule, N.O., Freeman, J.B., Moran, J.M., Gabrieli, J.D.E., Ambady, N., 2010. Voting behavior is reflected in amygdala response across cultures. Soc Cogn Aff Neurosci. 5, 349-355.

Saxe, R., Moran, J.M., Scholz, J., Gabrieli, J.D.E., 2006. Overlapping and non-overlapping brain regions for theory of mind and self reflection in individual subjects. Soc. Cogn. Aff. Neurosci. 1, 299-304.

Schiller, D., Freeman, J.B., Mitchell, J.P., Uleman, J.S., Phelps, E.A., 2009. A neural mechanism of first impressions. Nat. Neurosci. 12, 508-514.

Spezio, M.L., Rangel, A., Alvarez, R.M., O'Doherty, J.P., Mattes, K., Todorov, A., Kim, H., Adolphs, R., 2008. A neural basis for the effect of candidate appearance on election outcomes. Soc. Cogn. Aff. Neurosci. 3, 334-352.

Todorov, A., Engell, A.D., 2008. The role of the amygdala in implicit evaluation of emotionally neutral faces. Soc. Cogn. Aff. Neurosci. 3, 303-312.

Tzourio-Mazoyer, N., Landeau, B., Papathanassiou, D., Crivello, F., Etard, O., Delcroix, N. Mazoyer, B., Joliot, M., 2002. Automated anatomical labeling of activations in SPM using a macroscopic anatomical parcellation of the MNI MRI single-subject brain. Neuroimage 15, 273-289.

Van Bavel, J.J., Packer, D.J., Cunningham, W.A., 2008. The neural substrates of in-group bias: a functional magnetic resonance imaging investigation. Psychol. Sci. 19, 1131-1139.

Winston, J.S., Strange, B.A., O'Doherty, J., Dolan, R.J., 2002. Automatic and intentional responses during evaluation of trustworthiness of faces. Nat. Neurosci. 5, 277-283.

Winston, J.S., O'Doherty, J., Kilner, J.M., Perrett, D.I., Dolan, R.J., 2007. Brain systems for assessing facial attractiveness. Neuropsychologia 45, 195-206.

Zajonc, R.B., Adelman, P.K., Murphy, S.T., Niedenthal, P.M., 1987. Convergence in the physical appearance of spouses. Motiv. Emo. 11, 335-346.

Zebrowitz, L.A., 1997. Reading faces: window to the soul? Westview Press, Boulder, CO.

Zebrowitz, L.A., Montepare, J.M., Lee, H.K., 1993. They don't all look alike: individuated impressions of other racial groups. J. Pers. Soc. Psychol. 65, 85-101.

Zebrowitz, L.A., Collins, M.A., Dutta, R., 1998. The relationship between appearance and personality across the lifespan. Pers. Soc. Psychol. Bull. 24, 736-749. 